\title{
Adverse events associated with nafamostat mesylate and favipiravir treatment in COVID-19 patients
}

\author{
Toru Hifumi* (D), Shutaro Isokawa, Norio Otani and Shinichi Ishimatsu
}

Keywords: COVID-19, Adverse events, Nafamostat mesylate, Favipiravir

\section{Dear Sir:}

I read with interest the article "Nafamostat mesylate treatment in combination with favipiravir for patients critically ill with Covid-19: a case series" by Doi et al. [1]. The authors reported very low mortality rate $(9 \%, 1 / 11)$ with the combination nafamostat mesylate + favipiravir irrespective of high rate $(73 \%)$ of mechanically ventilated patients. Although nafamostat mesylate-related hyperkalemia developed in one patient, adverse events associated with such drug use were not precisely described. As both drugs were developed and used primarily limited to Japan, adverse event cases should be reported from Japan.

We treated 24 laboratory-confirmed coronavirus disease 2019 (COVID-19) patients admitted to the ICU during March 19 to April 30, 2020, in Tokyo. We encountered several complication cases associated with COVID-19 medications, including nafamostat mesylate and favipiravir (not their combination), and recently reported them in emergency medicine journals $[2,3]$.

Two COVID-19 cases diagnosed with neuroleptic malignant syndrome (NMS) and received favipiravir treatment (not the combination nafamostat mesylate + favipiravir) were recently published. In the letter for our manuscript, Prakash speculated that favipiravir induces serotonin syndrome (SS) probably due to its serotonergic properties [3]. Although the direct association between favipiravir and NMS/SS remains unknown, such central

\footnotetext{
* Correspondence: hifumitoru@gmail.com

Department of Emergency and Critical Care Medicine, St. Luke's International Hospital, 9-1 Akashi-cho, Chuo-ku, Tokyo 104-8560, Japan
}

nervous system (CNS) complications require special consideration.

Another complication case was diffuse microbleeding in brain treated with nafamostat mesylate and venovenous extracorporeal membrane oxygenation (VV-ECMO) [2]. A 56-year-old man with severe COVID-19 pneumonia admitted to the ICU received VV-ECMO on day 5 for severe hypoxia. Simultaneously, nafamostat mesylate $200 \mathrm{mg}$ /day was administered for 3 days. Careful coagulation monitoring was performed. He developed cognitive dysfunction; brain computed tomography revealed multiple subcortical hemorrhages. Follow-up cerebral magnetic resonance imaging demonstrated diffuse microbleeding in the subcortical area. Although cerebral hemorrhage causes remain unknown, we should focus on bleeding as nafamostat mesylate is a short-acting anticoagulant.

Therefore, although all three complication cases recovered well, serious adverse events, such as CNS and bleeding complications, require careful consideration when using these drugs in COVID-19 patients. Both efficacy and adverse events should be discussed simultaneously whenever providing new therapy.

\begin{abstract}
Abbreviations
COVID-19: Coronavirus disease 2019; NMS: Neuroleptic malignant syndrome; SS: Serotonin syndrome; CNS: Central nervous system; W-ECMO: Venovenous extracorporeal membrane oxygenation
\end{abstract}

\section{Acknowledgements \\ Not applicable}

\section{Authors' contributions}

All authors had full access to all of the data in the study and take responsibility for the integrity of the data and the accuracy of the data

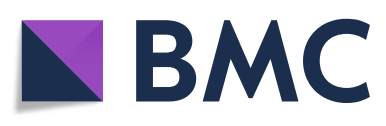

(c) The Author(s). 2020 Open Access This article is licensed under a Creative Commons Attribution 4.0 International License, which permits use, sharing, adaptation, distribution and reproduction in any medium or format, as long as you give appropriate credit to the original author(s) and the source, provide a link to the Creative Commons licence, and indicate if changes were made. The images or other third party material in this article are included in the article's Creative Commons licence, unless indicated otherwise in a credit line to the material. If material is not included in the article's Creative Commons licence and your intended use is not permitted by statutory regulation or exceeds the permitted use, you will need to obtain permission directly from the copyright holder. To view a copy of this licence, visit http://creativecommons.org/licenses/by/4.0/. The Creative Commons Public Domain Dedication waiver (http://creativecommons.org/publicdomain/zero/1.0/) applies to the data made available in this article, unless otherwise stated in a credit line to the data. 
analysis. Drafting of the manuscript: Toru Hifumi. The authors read and approved the final manuscript.

\section{Funding}

None

Availability of data and materials

The data of the three patients are available from the corresponding author on reasonable request.

Ethics approval and consent to participate

Not applicable

\section{Consent for publication}

Not applicable

\section{Competing interests}

The authors declare that they have no competing interests.

Received: 14 July 2020 Accepted: 5 August 2020

Published online: 12 August 2020

\section{References}

1. Doi K, Ikeda M, Hayase N, Moriya K, Morimura N, Group C-US. Nafamostat mesylate treatment in combination with favipiravir for patients critically ill with Covid-19: a case series. Crit Care. 2020;24(1):392

2. Isokawa S, Hifumi T, Ishimatsu S. Manwith severe COVID pneumonia. JACEP Open. 2020;1(1).

3. Soh M, Hifumi T, Isokawa S, Shimizu M, Otani N, Ishimatsu S. Neuroleptic malignant syndrome in patients with COVID-19. Am J Emerg Med. 2020; S0735-6757(20):30384-3.

\section{Publisher's Note}

Springer Nature remains neutral with regard to jurisdictional claims in published maps and institutional affiliations. 